\title{
PENGARUH PENERAPAN MODEL PEMBELAJARAN KOOPERATIF TIPE GI (GROUP INVESTIGATION) TERHADAP MOTIVASI BELAJAR SISWA SMA NEGERI 1 KINTAMANI
}

\author{
Ni Wayan Budiani, I Made Diarta \\ Program Studi Pendidikan Biologi \\ Fakultas Keguruan dan Ilmu Pendidikan \\ Universitas Mahasaraswati Denpasar
}

\begin{abstract}
ABSTRAK
The study was conducted to know the influence of implementing Cooperative Learning Model Group Investigation (GI) type toward students' motivation in learning. It was done by using batur Lake Geopark as the learning site. Design of the study is Non Equivalent pretest-posttest control group. The subject was all grade ten students of SMA Negeri 1 Kintamani in academic year 2012/2013. Through systematic sampling technique, there were 21 students for control group and 20 students for experiment group. The data was gathered by using quiestionaire, and then analyzed with non parametric statistics: Mann Whitney $U$ Test. The results showed that there is a significant influence toward students' learning motivation after having GI, around 254.11, sd=14.1.
\end{abstract}

Keywords: cooperative learning model group investigation type, motivation, batur Lake Geopark 


\section{PENDAHULUAN}

Belajar, menurut Robert Heinich dkk (2005) dalam (Benny, 2009) adalah sebuah proses pengembangan pengetahuan, keterampilan, dan sikap yang terjadi apabila seseorang melakukan interaksi secara intensif dengan sumber-sumber belajar.

Sedangkan pembelajaran menurut Walter Dick dan Lou Carey (2005) dalam (Benny, 2009) adalah rangkaian peristiwa atau kegiatan yang disampaikan secara terstruktur dan terencana dengan menggunakan sebuah atau beberapa jenis media.

Selama ini dalam proses belajar mengajar di kelas, khususnya pada pelajaran biologi sering kali disampaikan dengan metode ceramah yang disertai tanya jawab. Diduga pembelajaran seperti ini menyebabkan siswa menjadi pasif, karena pembelajaran didominasi oleh guru sehingga materi pelajaran dirasakan oleh siswa sebagai beban yang harus diingat, dan dihafal, namun kurang mampu dipahami oleh siswa, sehingga minat maupun motivasi belajar siswa menjadi berkurang dalam upaya penguasaan konsep-konsep biologi. Untuk mengatasi permasalahan tersebut yakni dengan menerapkan model pembelajaran yang memberikan kesempatan lebih kepada siswa untuk terlibat aktif dalam pembelajaran, salah satunya dengan menerapkan model pembelajaran Group Investigation (GI), dimana dalam pembelajaran ini salah satunya meliputi investigation yaitu melakukan pengamatan langsung pada lokasi yang akan dijadikan pembelajaran.

Penggunaan media dalam proses pembelajaran di sekolah, berhubungan dengan tingkat perkembangan psikologis serta tarap kemampuan siswa yang mengikuti proses pembelajaran dapat menarik minat dan memotivasi belajar siswa (Haryanto, 2012). Hal ini sejalan dengan pendapat Nana Sudjana dan Ahmad Rivai (1991) bahwa manfaat media dalam pembelajaran adalah (1) pembelajaran akan lebih menarik siswa sehingga dapat menumbuhkan motivasi belajar siswa, (2) pembelajaran akan lebih jelas maknanya sehinggga dapat lebih dipahami oleh para siswa dan memungkinkan siswa mencapai tujuan pembelajaran lebih baik, (3) dalam kegiatan belajar siswa tidak hanya mendengarkan uraian dari guru tetapi juga aktivitas lain seperti mengamati, melakukan maupun mendemonstrasikan sebuah materi dalam proses pembelajaran.

Berdasarkan latar belakang yang telah diuraikan, tujuan penelitiaan ini adalah untuk mengetahui pengaruh penerapan model pembelajaran kooperatif tipe GI berbasis ekopedagogi dengan memanfaatkan Geopark Danau Batur sebagai media pembelajaran di SMA Negeri 1 Kintamani.

\section{METODE PENELITIAN}

Penelitian ini menggunakan eksperimen semu, karena desain ini mempunyai kelompok kontrol, tetapi tidak dapat berfungsi sepenuhnya untuk mengontrol variabel-variabel luar yang mempengaruhi pelaksanaan eksperimen. Desain eksperimen yang digunakan adalah Non Equivalent Pretest-Posttest Control Group Design, yaitu ada kelompok eksperimen dan kelompok kontrol yang diberi pre-test dan post-test tetapi hanya kelas eksperimen yang diberi perlakuan dengan menerapkan model pembelajaran kooperatif tipe GI berbasis ekopedagogi. Subjek penelitian ini diambil tidak secara acak dari populasi tetapi seluruh subjek dari kelompok yang terbentuk secara alami (Sugiyono, 2010). Penelitian ini dilaksanakan dari bulan Januari sampai Maret 2013 di SMA Negeri 1 Kintamani. Penelitian ini ada 6 tahapan dalam pembelajaran kooperatif tipe GI menurut Trianto (2007), yaitu tahap grouping (siswa membagi diri dalam kelompok), planning (siswa merencanakan tugas), investigation (siswa melakukan penyelidikan), organizing (siswa mempersiapkan tugas akhir), presenting (siswa mempersentasikan hasil kerjanya), evaluating (penilaian proses kerja). Data motivasi belajar siswa dikumpulkan melalui angket yang memuat beberapa item yang terdiri dari 4 aspek motivasi yaitu perhatian, percaya diri, relevansi dan kepuasan dengan penskoran menggunakan skala Likert, yaitu tiap item mempunyai skor maksimal 5 dan skor minimal 1 . Sebelum digunakan, angket ini di uji validitas dan reliabilitas selanjutnya data dianalisis dengan uji Mann Whitney U Test. 


\section{HASIL DAN PEMBAHASAN}

\section{Hasil}

Penelitian ini difokuskan untuk mengetahui pengaruh penerapan model pembelajaran kooperatif tipe GI berbasis ekopedagogi terhadap motivasi belajar siswa. Proses pengambilan data penelitian ini dilaksanakan dari bulan Januari hingga Maret 2013 yang bertempat di SMA Negeri 1 Kintamani tahun pelajaran 2012/2013. Siswa yang dilibatkan dalam penelitian ini adalah siswa kelas Xg sebagai kelas kontrol yang berjumlah 21 orang dan kelas Xh sebagai kelas eksperimen dengan jumlah 20 siswa. Data yang dikumpulkan dalam penelitian ini adalah data motivasi belajar siswa yang terdiri dari 4 aspek motivasi yaitu Perhatian, Percaya Diri, Relevansi dan Kepuasan yang diberikan sebelum dan sesudah penerapan model pembelajaran kooperatif tipe GI berbasis ekopedagogi selama proses pembelajaran berlangsung.

Selanjutnya data yang diperoleh diuji dengan program SPSS dan dianalisis dengan uji statistik non parametrik Mann Whitney U Test. Hasil analisis data pada penelitian ini adalah sebagai berikut :

\section{Hasil Uji Validitas}

Uji coba angket motivasi belajar siswa yang dilaksanakan di kelas X SMA Negeri 1 kintamani. Hasil uji validitas menunjukan bahwa dari 36 item pernyataan yang diuji cobakan, 33 item dinyatakan valid $(\mathrm{P}<0,05)$ sehingga soal tersebut tidak digunakan untuk uji reliabilitas. 3 item soal yang tidak valid tersebut adalah item no 10 ( $\mathrm{S} 10=$ $0,388)$, no $26(\mathrm{~S} 26=0,129)$ dan no $31(\mathrm{~S} 31=0,861)$ sehingga dinyatakan tidak valid.

\section{Hasil Uji Reliabilitas}

Hasil uji reliabilitas instrument penelitian dapat dilihat pada tabel berikut :

Tabel 1. Hasil uji Reliabilitas.

Reliability Statistics

\begin{tabular}{|c|c|}
\hline Cronbach's Alpha & N of Items \\
\hline .962 & 33 \\
\hline
\end{tabular}

Hasil analisis uji coba instrument menunjukkan bahwa statistik Cronbach alpha $(\alpha=0,962)$ dengan jumlah item soal 33 item. Nilai $\alpha=0,962$ tergolong tinggi karena $\alpha \geq 0,60$ sehingga dapat dikatakan bahwa alat tes tersebut reliabel dan dapat digunakan.

\section{Data Motivasi Belajar Siswa}

Berdasarkan data yang diperoleh dari angket motivasi belajar siswa untuk pernyataan positif dan negatif dari 4 aspek motivasi (perhatian, percaya diri, relevansi, dan kepuasan), diperoleh suatu gambaran respon siswa terhadap proses pembelajaran yang telah diterapkan. Skor angket motivasi belajar siswa yang diperoleh dari pretest ke posttest mengalami peningkatan baik di kelas kontrol maupun di ke kelas eksperimen. Pada data tabulasi aspek motivasi belajar siswa dengan jumlah 33 item pernyataan dapat dilihat pada tabel 2 untuk di kelas kontrol dengan jumlah siswa 21 siswa dan pada tabel 3 untuk di kelas eksperimen yang terdiri dari 20 siswa, aspek seluruhnya mengalami peningkatan. 
Tabel 2. Skor Aspek Motivasi Belajar Siswa di Kelas Kontrol

\begin{tabular}{|c|c|c|c|c|c|c|c|c|c|c|c|c|c|c|}
\hline \multirow{2}{*}{$\begin{array}{r}\text { No } \\
\text { item }\end{array}$} & \multirow[b]{2}{*}{ Aspek } & \multicolumn{4}{|c|}{ Pretest } & \multirow{2}{*}{\multicolumn{2}{|c|}{$\begin{array}{lr}\text { Tot } \\
\text { STS }\end{array}$}} & \multicolumn{5}{|c|}{ Posttest } & \multirow[t]{2}{*}{ Tot } & \multirow[t]{2}{*}{ Ket } \\
\hline & & SS & $\mathbf{S}$ & $\mathbf{R}$ & TS & & & SS & $\mathbf{S}$ & $\mathbf{R}$ & TS & STS & & \\
\hline 1 & $\mathrm{P}(+)$ & 0 & 12 & 27 & 18 & 0 & 57 & 0 & 36 & 18 & 12 & 0 & 66 & + \\
\hline 2 & $\mathrm{P}(+)$ & 0 & 12 & 39 & 10 & 0 & 61 & 0 & 32 & 24 & 10 & 0 & 66 & + \\
\hline 3 & $\mathrm{P}(+)$ & 0 & 0 & 24 & 26 & 0 & 50 & 5 & 16 & 27 & 14 & 0 & 62 & + \\
\hline 4 & $\mathrm{P}(+)$ & 0 & 12 & 36 & 12 & 0 & 60 & 5 & 20 & 33 & 8 & 0 & 66 & + \\
\hline 5 & $\mathrm{P}(+)$ & 0 & 16 & 48 & 2 & 0 & 66 & 5 & 48 & 18 & 4 & 0 & 75 & + \\
\hline 6 & $\mathrm{P}(-)$ & 0 & 4 & 42 & 12 & 0 & 58 & 0 & 36 & 33 & 2 & 0 & 71 & + \\
\hline 7 & $\mathrm{P}(-)$ & 1 & 6 & 39 & 16 & 0 & 62 & 0 & 8 & 24 & 36 & 0 & 68 & + \\
\hline 8 & $\mathrm{P}(-)$ & 0 & 8 & 39 & 16 & 0 & 63 & 1 & 2 & 30 & 32 & 5 & 70 & + \\
\hline 9 & $\mathrm{P}(-)$ & 1 & 6 & 45 & 8 & 0 & 60 & 0 & 6 & 33 & 28 & 0 & 67 & + \\
\hline 10 & $\mathrm{PD}(+)$ & 0 & 4 & 54 & 4 & 0 & 62 & 0 & 36 & 30 & 4 & 0 & 70 & + \\
\hline 11 & $\mathrm{PD}(+)$ & 0 & 8 & 45 & 8 & 0 & 61 & 0 & 24 & 33 & 8 & 0 & 65 & + \\
\hline 12 & $\mathrm{PD}(+)$ & 5 & 8 & 42 & 6 & 1 & 62 & 0 & 60 & 3 & 6 & 2 & 71 & + \\
\hline 13 & $\mathrm{PD}(+)$ & 0 & 4 & 40 & 12 & 4 & 60 & 0 & 8 & 42 & 10 & 0 & 60 & + \\
\hline 14 & $\mathrm{PD}(+)$ & 1 & 0 & 36 & 16 & 0 & 53 & 0 & 24 & 30 & 10 & 0 & 64 & + \\
\hline 15 & PD (-) & 2 & 4 & 36 & 12 & 0 & 54 & 1 & 4 & 21 & 44 & 0 & 70 & + \\
\hline 16 & PD (-) & 4 & 4 & 27 & 14 & 0 & 49 & 0 & 24 & 24 & 14 & 0 & 62 & + \\
\hline 17 & PD (-) & 2 & 18 & 27 & 4 & 0 & 51 & 0 & 8 & 20 & 44 & 5 & 77 & + \\
\hline 18 & $\mathrm{R}(+)$ & 0 & 6 & 45 & 8 & 1 & 60 & 0 & 2 & 18 & 52 & 1 & 73 & + \\
\hline 19 & $\mathrm{R}(+)$ & 0 & 16 & 24 & 16 & 1 & 57 & 0 & 6 & 24 & 36 & 5 & 71 & + \\
\hline 20 & $\mathrm{R}(+)$ & 0 & 10 & 33 & 12 & 2 & 57 & 0 & 2 & 21 & 52 & 0 & 75 & + \\
\hline 21 & $\mathrm{R}(+)$ & 0 & 32 & 24 & 6 & 2 & 64 & 10 & 60 & 12 & 0 & 0 & 82 & + \\
\hline 22 & $\mathrm{R}(+)$ & 0 & 8 & 36 & 14 & 0 & 58 & 0 & 40 & 21 & 8 & 0 & 69 & + \\
\hline 23 & $\mathrm{R}(-)$ & 0 & 12 & 36 & 12 & 0 & 60 & 0 & 16 & 33 & 12 & 0 & 61 & + \\
\hline 24 & $\mathrm{R}(-)$ & 0 & 8 & 42 & 12 & 0 & 62 & 0 & 0 & 30 & 40 & 5 & 75 & + \\
\hline 25 & $\mathrm{R}(-)$ & 1 & 4 & 33 & 28 & 0 & 66 & 0 & 4 & 27 & 40 & 0 & 71 & + \\
\hline 26 & $\mathrm{KP}(+)$ & 0 & 28 & 33 & 6 & 0 & 67 & 0 & 52 & 18 & 2 & 0 & 72 & + \\
\hline 27 & $\mathrm{KP}(+)$ & 0 & 36 & 21 & 8 & 1 & 66 & 5 & 36 & 33 & 0 & 0 & 74 & + \\
\hline 28 & $\mathrm{KP}(+)$ & 0 & 48 & 21 & 4 & 0 & 73 & 10 & 44 & 15 & 6 & 0 & 75 & + \\
\hline 29 & $\mathrm{KP}(+)$ & 0 & 36 & 18 & 8 & 2 & 64 & 10 & 40 & 33 & 0 & 0 & 83 & + \\
\hline 30 & $\mathrm{KP}(+)$ & 0 & 28 & 27 & 10 & 0 & 65 & 5 & 52 & 30 & 2 & 0 & 89 & + \\
\hline 31 & $\mathrm{KP}(-)$ & 0 & 10 & 33 & 20 & 0 & 63 & 0 & 2 & 24 & 44 & 5 & 75 & + \\
\hline 32 & $\mathrm{KP}(-)$ & 1 & 2 & 24 & 44 & 0 & 71 & 0 & 0 & 36 & 28 & 10 & 74 & + \\
\hline 33 & $\mathrm{KP}(-)$ & 0 & 4 & 30 & 36 & 0 & 70 & 0 & 2 & 27 & 44 & 0 & 73 & + \\
\hline
\end{tabular}

Keterangan: SS (sangat setuju), S (setuju), R (ragu), TS (tidak setuju), STS (sangat tidak setuju), (+) mengalami peningkatan, (-) mengalami penurunan

Tabel 3: Skor Aspek Motivasi Belajar Siswa pada Kelas Eksperimen

\begin{tabular}{|c|c|c|c|c|c|c|c|c|c|c|c|c|c|c|}
\hline \multirow{2}{*}{$\begin{array}{l}\text { No } \\
\text { item }\end{array}$} & \multirow[b]{2}{*}{ Aspek } & \multicolumn{5}{|c|}{ Pretest } & \multirow[b]{2}{*}{ Tot } & \multicolumn{5}{|c|}{ Postest } & \multirow[b]{2}{*}{ Tot } & \multirow[b]{2}{*}{ Ket } \\
\hline & & SS & $\mathbf{S}$ & $\mathbf{R}$ & TS & STS & & SS & $\mathbf{S}$ & $\mathbf{R}$ & TS & STS & & \\
\hline 1 & $\mathrm{P}(+)$ & 5 & 40 & 15 & 8 & 0 & 68 & 20 & 52 & 9 & 0 & 0 & 81 & $(+)$ \\
\hline 2 & $\mathrm{P}(+)$ & 0 & 24 & 30 & 2 & 3 & 59 & 30 & 44 & 9 & 0 & 0 & 83 & $(+)$ \\
\hline 3 & $\mathrm{P}(+)$ & 0 & 8 & 42 & 8 & 0 & 58 & 0 & 52 & 21 & 0 & 0 & 73 & $(+)$ \\
\hline 4 & $\mathrm{P}(+)$ & 0 & 28 & 30 & 4 & 1 & 63 & 5 & 48 & 21 & 0 & 0 & 74 & $(+)$ \\
\hline 5 & $\mathrm{P}(+)$ & 0 & 40 & 24 & 2 & 1 & 67 & 25 & 56 & 3 & 0 & 0 & 84 & $(+)$ \\
\hline 6 & $P(-)$ & 0 & 20 & 18 & 16 & 0 & 54 & 15 & 48 & 15 & 0 & 0 & 78 & $(+)$ \\
\hline 7 & $\mathrm{P}(-)$ & 2 & 6 & 27 & 24 & 0 & 59 & 0 & 0 & 3 & 56 & 25 & 84 & $(+)$ \\
\hline 8 & $\mathrm{P}(-)$ & 0 & 10 & 21 & 32 & 0 & 63 & 0 & 2 & 12 & 40 & 25 & 79 & $(+)$ \\
\hline 9 & $\mathrm{P}(-)$ & 0 & 8 & 21 & 36 & 0 & 65 & 1 & 2 & 6 & 44 & 20 & 73 & $(+)$ \\
\hline 10 & $\mathrm{PD}(+)$ & 0 & 48 & 15 & 4 & 1 & 68 & 20 & 48 & 12 & 0 & 0 & 80 & $(+)$ \\
\hline 11 & PD (+) & 0 & 16 & 30 & 10 & 1 & 57 & 15 & 52 & 9 & 2 & 0 & 78 & $(+)$ \\
\hline 12 & $\mathrm{PD}(+)$ & 5 & 48 & 18 & 4 & 0 & 75 & 35 & 32 & 12 & 2 & 0 & 81 & $(+)$ \\
\hline 13 & PD (+) & 0 & 36 & 15 & 10 & 1 & 62 & 10 & 44 & 21 & 0 & 0 & 75 & $(+)$ \\
\hline 14 & PD (+) & 5 & 20 & 30 & 6 & 1 & 62 & 20 & 56 & 3 & 2 & 0 & 81 & $(+)$ \\
\hline 15 & PD (-) & 0 & 6 & 21 & 40 & 0 & 67 & 0 & 2 & 12 & 60 & 0 & 74 & $(+)$ \\
\hline 16 & PD (-) & 5 & 28 & 24 & 6 & 1 & 64 & 0 & 2 & 18 & 44 & 10 & 74 & $(+)$ \\
\hline 17 & PD (-) & 0 & 6 & 15 & 48 & 5 & 74 & 0 & 52 & 12 & 0 & 15 & 79 & $(+)$ \\
\hline
\end{tabular}




\begin{tabular}{cllllllllllllll}
\hline 18 & $\mathrm{R}(+)$ & 5 & 10 & 18 & 32 & 0 & $\mathbf{6 5}$ & 25 & 28 & 24 & 0 & 0 & $\mathbf{7 7}$ & $(+)$ \\
\hline 19 & $\mathrm{R}(+)$ & 0 & 10 & 30 & 20 & 0 & $\mathbf{6 0}$ & 15 & 44 & 12 & 4 & 0 & $\mathbf{7 5}$ & $(+)$ \\
\hline 20 & $\mathrm{R}(+)$ & 0 & 40 & 24 & 2 & 1 & $\mathbf{6 7}$ & 25 & 48 & 9 & 0 & 0 & $\mathbf{8 2}$ & $(+)$ \\
\hline 21 & $\mathrm{R}(+)$ & 5 & 36 & 21 & 4 & 1 & $\mathbf{6 7}$ & 20 & 48 & 12 & 0 & 0 & $\mathbf{8 0}$ & $(+)$ \\
\hline 22 & $\mathrm{R}(+)$ & 0 & 28 & 30 & 6 & 0 & $\mathbf{6 4}$ & 15 & 44 & 18 & 0 & 0 & $\mathbf{7 7}$ & $(+)$ \\
\hline 23 & $\mathrm{R}(-)$ & 0 & 8 & 9 & 52 & 0 & $\mathbf{6 9}$ & 0 & 0 & 18 & 48 & 10 & $\mathbf{7 6}$ & $(+)$ \\
\hline 24 & $\mathrm{R}(-)$ & 0 & 16 & 27 & 12 & 0 & $\mathbf{5 5}$ & 0 & 0 & 12 & 32 & 40 & $\mathbf{8 4}$ & $(+)$ \\
\hline 25 & $\mathrm{R}(-)$ & 1 & 4 & 15 & 40 & 10 & $\mathbf{7 0}$ & 0 & 0 & 27 & 40 & 5 & $\mathbf{7 2}$ & $(+)$ \\
\hline 26 & $\mathrm{KP}(+)$ & 5 & 48 & 9 & 8 & 0 & $\mathbf{7 0}$ & 5 & 52 & 18 & 0 & 0 & $\mathbf{7 5}$ & $(+)$ \\
\hline 27 & $\mathrm{KP}(+)$ & 0 & 2 & 33 & 32 & 0 & $\mathbf{6 7}$ & 5 & 36 & 30 & 0 & 0 & $\mathbf{7 1}$ & $(+)$ \\
\hline 28 & $\mathrm{KP}(+)$ & 5 & 32 & 18 & 8 & 1 & $\mathbf{6 4}$ & 15 & 36 & 24 & 0 & 0 & $\mathbf{7 5}$ & $(+)$ \\
\hline 29 & $\mathrm{KP}(+)$ & 5 & 32 & 27 & 2 & 1 & $\mathbf{6 7}$ & 10 & 40 & 24 & 0 & 0 & $\mathbf{7 4}$ & $(+)$ \\
\hline 30 & $\mathrm{KP}(+)$ & 0 & 40 & 21 & 6 & 0 & $\mathbf{6 7}$ & 5 & 44 & 24 & 4 & 0 & $\mathbf{7 7}$ & $(+)$ \\
\hline 31 & $\mathrm{KP}(-)$ & 0 & 32 & 21 & 8 & 5 & $\mathbf{6 2}$ & 0 & 0 & 30 & 36 & 5 & $\mathbf{7 1}$ & $(+)$ \\
\hline 32 & $\mathrm{KP}(-)$ & 0 & 4 & 42 & 16 & 0 & $\mathbf{6 2}$ & 0 & 0 & 12 & 56 & 10 & $\mathbf{7 8}$ & $(+)$ \\
\hline 33 & $\mathrm{KP}(-)$ & 0 & 4 & 24 & 40 & 0 & $\mathbf{6 8}$ & 0 & 0 & 21 & 40 & 15 & $\mathbf{7 6}$ & $(+)$ \\
\hline
\end{tabular}

Keterangan: SS (sangat setuju), S (setuju), R (ragu), TS (tidak setuju), STS (sangat tidak setuju), (+) mengalami peningkatan, (-) mengalami penurunan.

Setelah melakukan penskoran pada angket motivasi belajar siswa, data selanjutnya akan dijumlahkan untuk membandingkan nilai yang diperoleh pada kelas kontrol dengan model pembelajaran konvensional dan kelas eksperimen dengan penerapan model pembelajaran kooperatif tipe GI berbasis ekopedagogi dengan memanfaatkan Geopark Danau Batur sebagai media pembelajaran dengan mencari nilai rata-rata skor yang diperoleh siswa kelas X SMA Negeri 1 Kintamani. Data tersebut dapat dilihat pada tabel 4 berikut.

Tabel 4: Data Angket Motivasi Belajar siswa kelas Kontrol dan kelas Eksperimen

\begin{tabular}{lcc}
\hline \multicolumn{1}{c}{ Statistik } & Kontrol & Eksperimen \\
\hline $\mathrm{N}$ & 21 & 20 \\
\hline Rata-rata & 224,9 & 254,1 \\
\hline Standar Deviasi & 21.9 & 14.1 \\
\hline Skor Tertinggi & 252 & 282 \\
\hline Skor Terendah & 199 & 229 \\
\hline
\end{tabular}

Dari data pada tabel 4. dapat diketahui nilai rata-rata dari pretest ke posttest pada kelas kontrol sebesar 224,9 dengan standar deviasi 21,9 sedangkan rata-rata motivasi belajar pada kelas eksperimen dari pretest ke posttest sebesar 254,1 dengan standar deviasi 14,1. Standar deviasi yang semakin kecil menunjukan bahwa motivasi belajar siswa semakin baik. Dari kedua tabulasi skor aspek motivasi belajar siswa yang membandingkan kelas kontrol dan kelas eksperimen dapat dilihat pada gambar berikut:

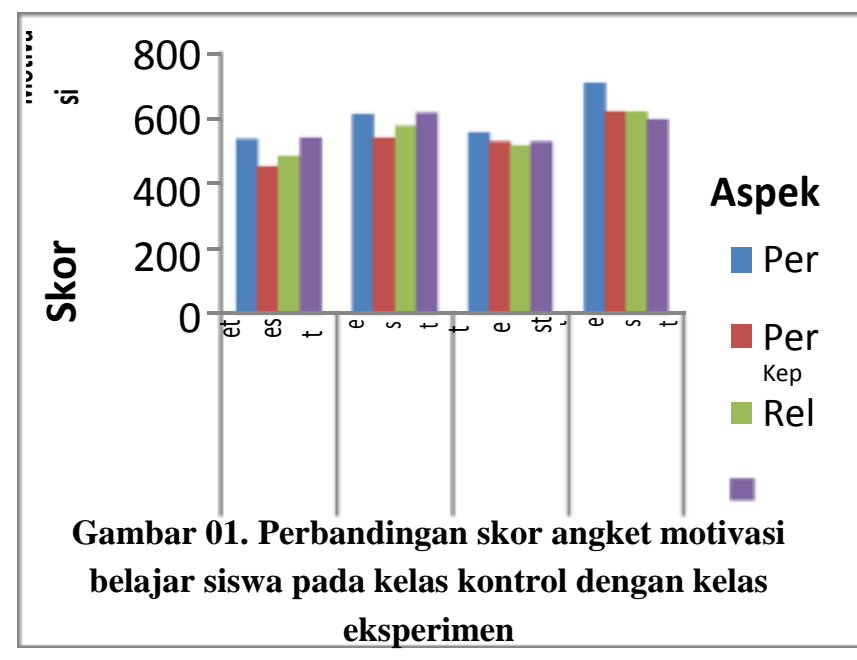

Berdasarkan hasil grafik diatas terjadi peningkatan skor angket motivasi belajar siswa di kelas kontrol dari hasil pretest ke posttest begitu juga di kelas eksperimen. Aspek motivasi di kelas kontrol dengan skor tertinggi ada pada aspek kepuasan baik pretest maupun postest, dengan jumlah skor pada saat pretest sebesar 539 dan pada saat postest skor seluruh aspek kepuasan sebesar 615 pada saat posttest. Skor motivasi belajar siswa di kelas eksperimen dari hasil pretest ke posttest yang mencapai jumlah skor tertinggi adalah pada aspek Perhatian dengan skor 556 pada saat pretest dan 709 pada saat posttest. Selanjutnya data angket motivasi belajar siswa dianalisis dengan uji statistic non parametrik Mann Whitney $U$ Test dengan bantuan SPSS 16 for windows (2007). Dapat dilihat pada tabel berikut: 
Tabel 5. Hasil analisis angket motivasi belajar siswa dengan uji Mann Whitney $U$ Test.

\begin{tabular}{lc}
\hline & Motivasi \\
\hline Mann-Whitney U & 17.500 \\
\hline Wilcoxon W & 248.500 \\
\hline Z & -5.023 \\
\hline Asymp.Sig.(2-tailed) & .000 \\
\hline
\end{tabular}

Berdasarkan hasil uji analisis pada tabel 5, nilai signifikansi $p$ sebesar $0.000(<0.05)$ maka hipotesis nol (Ho) ditolak, artinya bahwa terdapat perbedaan nilai motivasi belajar siswa di kelas kontrol dan di kelas eksperimen, sehingga dapat disimpulkan bahwa terdapat pengaruh model pembelajaran kooperatif tipe GI terhadap motivasi belajar siswa kelas $\mathrm{X}$ pada pokok bahasan keanekaragaman hayati dengan memanfaatkan geopark danau batur sebagai media pembelajaran untuk SMA negeri 1 Kintamani.

\section{PEMBAHASAN}

Sebelum digunakan pengambilan data, terlebih dahulu dilakukan uji validitas instrument sebelum memberikan pretest dan posttest pada kelas eksperimen maupun kelas kontrol, soal yang valid untuk digunakan dalam pengambilan data sebanyak 33 pernyataan dari 36 pernyataan yang dibuat. Berdasarkan analisis data motivasi belajar siswa didapat bahwa motivasi belajar siswa dari S-1 sampai S -21 mengalami peningkatan dari hasil pretest ke posttest untuk dikelas kontrol begitu juga pada kelas eksperimen. Peningkatan motivasi belajar siswa tersebut dilihat dari rata-rata motivasi belajar siswa yang diperoleh melalui angket.

Pada pretest motivasi belajar siswa untuk kelas kontrol nilai rata-rata sebesar 103, 8 dan hasil post-tes sebesar 121, 1 sedangkan pada kelas eksperimen nilai rata-rata hasil pretest sebesar 115,6 dan posttest sebesar 138,5. Secara signifikan penerapan model pembelajaran kooperatif tipe GI berpengaruh terhadap motivasi belajar siswa karena nilai $p$ adalah $0,000<0,05$.

Peningkatan skor motivasi belajar siswa ini disebabkan karena penerapan model pembelajaran kooperatif tipe GI berbasis ekopedagogi terdapat tahapan-tahapan yang dapat menumbuhkan motivasi belajar siswa. Penelitian Praptiningsih (2012) tentang penerapan metode pembelajaran kooperatif tipe GI dalam mata kuliah Ekoliterasi Ketahanan hayati (EKH) menyebutkan bahwa pembelajaran kooperatif mampu meningkatkan berbagai kemampuan akademik serta peningkatan sosial mahasiswa, karena pembelajaran kooperatif tidak hanya metode pembelajaran yang hanya sekedar berkelompok, namun merupakan pembelajaran yang memberikan dorongan berupa tugas yang bersifat kooperatif sehingga memung-kinkan terjadinya interaksi terbuka diantara anggota kelompok. Disebutkan pula dalam penelitian Putra (2006) dalam Praptiningsih (2012), tentang pengguanaan media bergambar berbasis pendekatan komunikasi bahwa penggunaan media gambar yang dikombinasikan dengan adanya komunikasi, adanya saling interaksi dapat meningkatkan daya ingat, pemahaman informasi, terpacunya siswa untuk berbicara dan mengemukakan pendapat. Hal ini dapat dilihat dari penilaian aspek motivasi yang meliputi aspek (perhatian, percaya diri, relevansi dan kepuasan) yang mengalami peningkatan dari pretest ke post-tes. Dengan adanya kesempatan siswa memanfaatkan kawasan geopark danau batur sebagai media pembelajaran, siswa dapat secara langsung belajar dari apa yang mereka lihat, sehingga materi yang mereka pelajari akan lebih mudah dipahami.

Langkah-langkah yang ada pada model ini seperti mengidentifikasi topik, mengumpulkan data kemudian menarik suatu kesimpulan dari data-data tersebut dan terakhir mempresentasikan hasil kerja kelompoknya. Pada tahap ini tujuannya adalah memancing sejauh mana kemampuan siswa dalam mengkomunikasikan apa yang mereka dapatkan dari hasil penyelidikan yang telah dilakukan dan guru hanya menjelaskan secara garis besar mengenai materi yang akan dibahas.

Selanjutnya tahap evaluasi, hal ini melatih kemampuan berpikir khususnya penalaran siswa. Sehingga ketika di akhir pembelajaran diberikan tes kemampuan berfikir, mereka tidak merasa kesulitan dalam menjawab soal-soal tersebut karena kemampuan berfikir mereka sudah terlatih ketika pembelajaran dengan menggunakan model kooperatif tipe Group Investigation ini. 
Keanekaragaman hayati di geopark danau batur ini cocok diterapkan pada pembelajaran dengan menggunakan model pembelajaran ini karena materinya yang luas sehingga memudahkan siswa dalam memilih topik permasalahan yang akan mereka investigasi. Dalam penelitian ini tentunya terdapat hambatan yang dialami, hambatan tersebut adalah saat siswa di ajak melakukan pengamatan tentang keanekaragaman hayati di kawasan geopark danau batur tidak bisa dikontrol secara ketat bagaimana motivasi belajar siswa tersebut karena masih terlihat beberapa siswa malas untuk melakukan tugas yang harus mereka kerjakan pada kelompoknya masing-masing, untuk itu dalam penelitian ini harus benar-benar diawasi secara ketat bagaimana siswa bekerja dalam kelompoknya agar tidak didominasi oleh siswa yang lebih pintar, selain itu waktu yang digunakan untuk penelitian ini harus diperhitungkan dengan baik agar siswa tidak cepat bosan atau merasa jenuh.

\section{PENUTUP}

\section{Simpulan}

Berdasarkan hasil analisis data dan hasil penelitian dapat disimpulkan bahwa model pembelajaran kooperatif tipe GI berbasis ekopedagogi berpengaruh terhadap motivasi belajar siswa yang dilihat dari peningkatan motivasi belajar siswa dari pretest ke posttest, dan secara signifikan berdasarkan uji Mann Whitney $U$ Test nilai $\mathrm{p}=0,000$ $<0,05$ yang berarti model pembelajaran kooperatif tipe GI (Group Investigation) berpengaruh terhadap motivasi belajar siswa dengan memanfaatkan geopark danau batur sebagai media pembelajaran.

\section{Saran}

Berdasarkan hasil penelitian yang telah dilakukan maka saran yang dapat diberikan yaitu:

1. Bagi sekolah agar memberikan informasi dan memotivasi tenaga kependidikan agar lebih menerapkan metode pembelajaran yang kreatif dan inovatif melalui model pembelajaran kooperatif tipe GI (group investigation).

2. Disarankan bagi para guru untuk mencoba mengimplementasikan model pembelajaran kooperatif tipe GI dalam proses pembelajaran sebagai alternatif pembelajaran agar siswa tidak jenuh dalam mengikuti kegiatan pembelajaran.

3. Diharapkan kepada siswa agar penerapan model pembelajaran kooperatif tipe GI ini mampu memberikan pengalaman serta mengasah keterampilan untuk lebih aktif dalam kegiatan pembelajaran agar siswa lebih terlatih dan terbiasa untuk memecahkan masalah serta meningkatkan kemampuan dalam berkomunikasi baik secara perorangan maupun kelompok sehingga akan memberikan dampak yang baik

\section{DAFTAR PUSTAKA}

Benny A. Pribadi. (2009). Langkah penting merancang kegiatan pembelajaran yang efektif dan berkualitas Model Desain Sistem Pembelajaran. Jakarta: Dian Rakyat.

Haryanto. (2012). Media pembelajaran. Tersedia dalam http://belajar psikologi.com/pengertian-media-pembelajaran/. Diakses tanggal 20 juli 2013

Praptiningsih, DS., dan Surata, SPK. (2012). Efektivitas pembelajaran kooperatif terhadap peningkatan prestasi akademik, kohesi social kelas dan kohesi social kelompok bagi mahasiswa calon guru. Jurnal Santiaji Pendidikan. Vol.2 No.1 (2012) : 26-36.

Sugiyono. (2010). Metode penelitian pendidikan (pendekatan kuantitatif, kualitatif dan $R \& D$ ). Bandung: Alfabeta.

Surata, SPK. (2012). Mata kuliah ekopedagogi. Tersedia pada http://kalersurata.net/course/ info.php?id=6. Diakses tanggal 3 januari 2013.

Trianto, S.Pd. (2007). Model-model pembelajaran inovatif berorientasi kontruktivistik konsep, landasan teoritis-praktis dan implementasinya. Jakarta: Prestasi Pustaka. 
